\title{
BMR
}

\section{Genomic identification, phylogeny, and expression analysis of $M L O$ genes involved in susceptibility to powdery mildew in Fragaria vesca}

L.X. Miao ${ }^{1}$, M. Jiang ${ }^{2}$, Y.C. Zhang ${ }^{1}$, X.F. Yang ${ }^{1}$, H.Q. Zhang ${ }^{1}$, Z.F. Zhang ${ }^{1}$, Y.Z. Wang ${ }^{1}$ and G.H. Jiang ${ }^{1}$

${ }^{1}$ Institute of Horticulture, Zhejiang Academy of Agricultural Sciences, Hangzhou, Zhejiang, China

${ }^{2}$ College of Life Science, Taizhou University, Linhai, Zhejiang, China

Correspondence author: G.H. Jiang

E-mail: jgh2004267@sina.cn

Genet. Mol. Res. 15 (3): gmr. 15038400

Received January 7, 2016

Accepted March 11, 2016

Published August 5, 2016

DOI http://dx.doi.org/10.4238/gmr.15038400

Copyright (C) 2016 The Authors. This is an open-access article distributed under the terms of the Creative Commons Attribution ShareAlike (CC BY-SA) 4.0 License.

ABSTRACT. The $M L O$ (powdery mildew locus O) gene family is important in resistance to powdery mildew (PM). In this study, all of the members of the $M L O$ family were identified and analyzed in the strawberry (Fragaria vesca) genome. The strawberry contains at least 20 members of the $M L O$ family, and the protein sequence contained between 171 and 1485 amino acids, with 0-34 introns. Chromosomal localization showed that the $M L O$ s were unevenly distributed on each of the chromosomes, except for chromosome 4 . The greatest number of $M L O \mathrm{~s}$ (seven) was found on chromosome 3. A phylogenetic tree showed that the $M L O$ s were divided into seven groups (I-VII), four 
of which consisted of $M L O$ s from strawberry, Arabidopsis thaliana, rice, and maize, suggesting that these genes may have evolved after the divergence of monocots and dicots. Multiple sequence alignment showed that strawberry $M L O$ candidates related to powdery mildew resistance possessed seven highly conserved transmembrane domains, a calmodulin-binding domain, and two conserved regions, all of which are important domains for powdery mildew resistance genes. Expressed sequence tag analysis revealed that the $M L O$ s were induced by multiple abiotic stressors, including low and high temperature, drought, and high salinity. These findings will contribute to the functional characterization of $M L O$ s related to PM susceptibility, and will assist in the development of disease resistance in strawberries.

Key words: Strawberry; $M L O$; Bioinformatics; Phylogenic relationship

\section{INTRODUCTION}

Powdery mildew (PM) is one of the most important diseases in plants. Four major PM causal agents have been identified in the family Rosaceae: Podosphaera leucotricha, Sphaerotheca pannosa var. persicae, Podosphaera tridactyla, and Podosphaera aphanis (syn. Sphaerotheca macularis f. sp fragariae) (Boesewinkel, 1979; Xiao et al., 2001; Foulongne et al., 2003; Turechek et al., 2004). PM in strawberry is caused by the obligate pathogenic fungus S. macularis f. sp fragariae, and affects leaves, flowers, and fruit (Amsalem et al., 2006). These four fungi cause similar PM symptoms (Pessina et al., 2014).

$M L O$ (powdery mildew locus $\mathrm{O}$ ) is a plant-specific gene family that has seven complete transmembrane domains (TM1-TM7) (Büschges et al., 1997; Devoto et al., 1999). In barley, recessive mutations in $M L O$ genes confer durable broad-spectrum resistance to all known isolates of the barley PM fungus (Büschges et al., 1997), and were the first genes that are resistant to PM to be cloned (Piffanelli et al., 2004). Further research showed that $M L O$ genes encode calmodulin-binding proteins, and that calmodulin binding increases the susceptibility of barley to PM (Kim et al., 2002b). MLOs in barley possess the dual function of the regulation of disease resistance and leaf cell death (Devoto et al., 2003). Although $M L O$ s were first isolated as PM resistance genes in monocots (Büschges et al., 1997), some members of this family also play a role in modulating hosts' responses to PM in dicots, such as Arabidopsis (Consonni et al., 2006) and tomato (Bai et al., 2008). Therefore, $M L O$ disease resistance genes are extensively involved in interactions between plants and PM.

Many studies have shown that $M L O$ s only exist in plants. $M L O$ s have been identified in six plant taxa, including Arabidopsis, maize, rice, and grapevine (Devoto et al., 2003; Liu and Zhu, 2008; Feechan et al., 2009). In addition, MLOs that modulate hosts' responses to PM have been cloned in several plant species. For example, Arabidopsis AtMLO02, AtMLO06, and AtMLO12 exhibit significantly reduced susceptibility to Golovinomyces orontii and complete PM resistance (Consonni et al., 2006). In the tomato, the absence of MLOs increases PM resistance (Bai et al., 2008). Therefore, biologically active $M L O$ s may be a general requirement for PM pathogenesis in higher plants.

Genetics and Molecular Research 15 (3): gmr.15038400 
Recently, PM disease resistance has been reported in cucumber, wheat, and grapevine (Zhou et al., 2013; Alam et al., 2014; Lu et al., 2014; Zhang et al., 2014). In strawberry (Fragaria $\mathrm{x}$ ananassa Duchesne), cleaved amplified polymorphic sequence markers related to PM resistance have been developed (Heejeong et al., 2015), and interactions between strawberry and PM have been revealed using the RNA-seq method (Sun et al., 2015). Remarkably, the antisense expression of the peach PpMlo1 gene confers cross-species resistance to PM in Fragaria $\mathrm{x}$ ananassa (Jiwan et al., 2013).

The availability of the strawberry genome sequence provides a good platform for our understanding of the structural characteristics and phylogenetic relationships of the $M L O$ gene family at the whole-genome level. In this study, MLOs were identified by the integration of intron-exon structural characteristics, phylogenetic relationships, chromosome mapping, and expression analysis, which will provide the foundation for the further cloning of strawberry $M L O(F v M L O)$ resistance genes.

\section{MATERIAL AND METHODS}

\section{Datasets}

Information regarding $F v M L O$ family members was obtained from https://www. rosaceae.org/, $M L O$ s from Arabidopsis were obtained from http://www.arabidopsis.org/, and $M L O$ s from rice, grapevine, poplar, and sorghum were obtained from https://phytozome.jgi. doe.gov/pz/portal.html.

\section{Identification of $M L O \mathrm{~s}$ in strawberry and other model plants}

Strawberry genome sequence data were downloaded from https://www.rosaceae. org/ to establish a local database using the BioEdit software. To identify MLOs in the strawberry, two methods were used to search the local database. Firstly, MLOs in the strawberry were identified using MLO protein sequences from two model plant species (Arabidopsis thaliana and rice) as a query using the BLASTP tool. The query sequences were taken from previously published data on these two plants (Devoto et al., 2003; Liu and Zhu, 2008). Secondly, the hidden Markov models profile of the MLO domain (PF03106) in the Pfam database (http://pfam.sanger.ac.uk/) was exploited for the identification of $M L O$ s in the strawberry genome local database using HMMER 3.0 (http://hmmer.org/). The default parameters were used. Subsequently, all of the MLO protein sequences were analyzed to confirm the presence of an MLO domain using the SMART program (http:// smart.embl-heidelberg.de/).

\section{Sequence alignment and phylogenetic tree construction}

In order to analyze the evolutionary relationships between the members of the $M L O$ gene family, MLO proteins from strawberry and A. thaliana, grapevine, tomato, and pea were constructed using a phylogenetic tree (Devoto et al., 2003; Bai et al., 2008; Feechan et al., 2009; Pavan et al., 2011). The ClustalX program in BioEdit was used for the multiple sequence alignment of the amino acid sequence of strawberry MLO proteins (FvMLO). The

Genetics and Molecular Research 15 (3): gmr.15038400 
phylogenetic tree was constructed using the MEGA 5.0 software (Tamura et al., 2011), and was assessed using the bootstrap method (1000 iterations).

\section{Structural analysis of $F v M L O$ s}

To ascertain the exon/intron positions and phases of the $F v M L O$ s, we used the Gene Structure Display Server (http://gsds.cbi.pku.edu.cn/) to identify exon/intron structures using coding and genomic sequences (Guo et al., 2007).

\section{Chromosomal localization and conserved motif analysis of $F v M L O \mathrm{~s}$}

The chromosomal distributions of the $M L O$ s were determined using the Strawberry Genome Annotation Project (https://www.rosaceae.org/), and were displayed using the MapDraw V2.1 software (Liu and Meng, 2003). Conserved motifs of the FvMLO protein were analyzed using MEME (http://meme-suite.org/), and the parameters were set as follows: the minimum length of the conserved motif was 15 , the maximum length was 50 , and the maximum conserved motif was 10 .

\section{Expression profiles of $F v M L O$ s under different abiotic stressors}

To investigate $F v M L O$ expression profiles in stressed (low temperature, high temperature, drought, and high salinity) seedlings, the Genome Database for Rosaceae (http:// www.rosaceae.org/) was searched using the identified encoding sequences of the FvMLOs. Expressed sequence tags (ESTs) from the stressed seedlings were selected for analysis, and the nucleotide BLAST (BLASTn) program was used to search the ESTs that corresponded to the $F v M L O$ s investigated in this study.

\section{RESULTS}

\section{Identification of FvMLOs}

We retrieved $20 M L O$ genes from the strawberry genome ( $F v M L O 01-F v M L O 20$ ). Five of these may have been pseudogenes, as they encoded truncated proteins. The remaining 15 MLOs were between 1305 (FvMLO16) and 4458 (FvMLO14) bp in length, contained between $434(F v M L O 16)$ and 1485 ( $F v M L O 14)$ amino acids, and weighed between $48.67(F v M L O 16)$ and $166.95(F v M L O 14) \mathrm{kDa}$. The isoelectric points of most of the MLO proteins ranged from 7 to 10, with the highest being 10.04 (FvMLO01) and the lowest 5.92 ( FvMLO16) (Table 1).

The phylogenetic tree showed that the $F v M L O$ s could be divided into three groups, $\mathrm{A}, \mathrm{B}$, and $\mathrm{C}$, which contained 10, 3, and 7 members, respectively (Figure 1). The intronexon structural analysis revealed that changes in the number of introns varied, suggesting that structures among the members of this gene family are complex. Only three genes ( FvMLO04, $F v M L O 06$, and $F v M L O 12$ ) contained three introns or less.

Genetics and Molecular Research 15 (3): gmr.15038400 


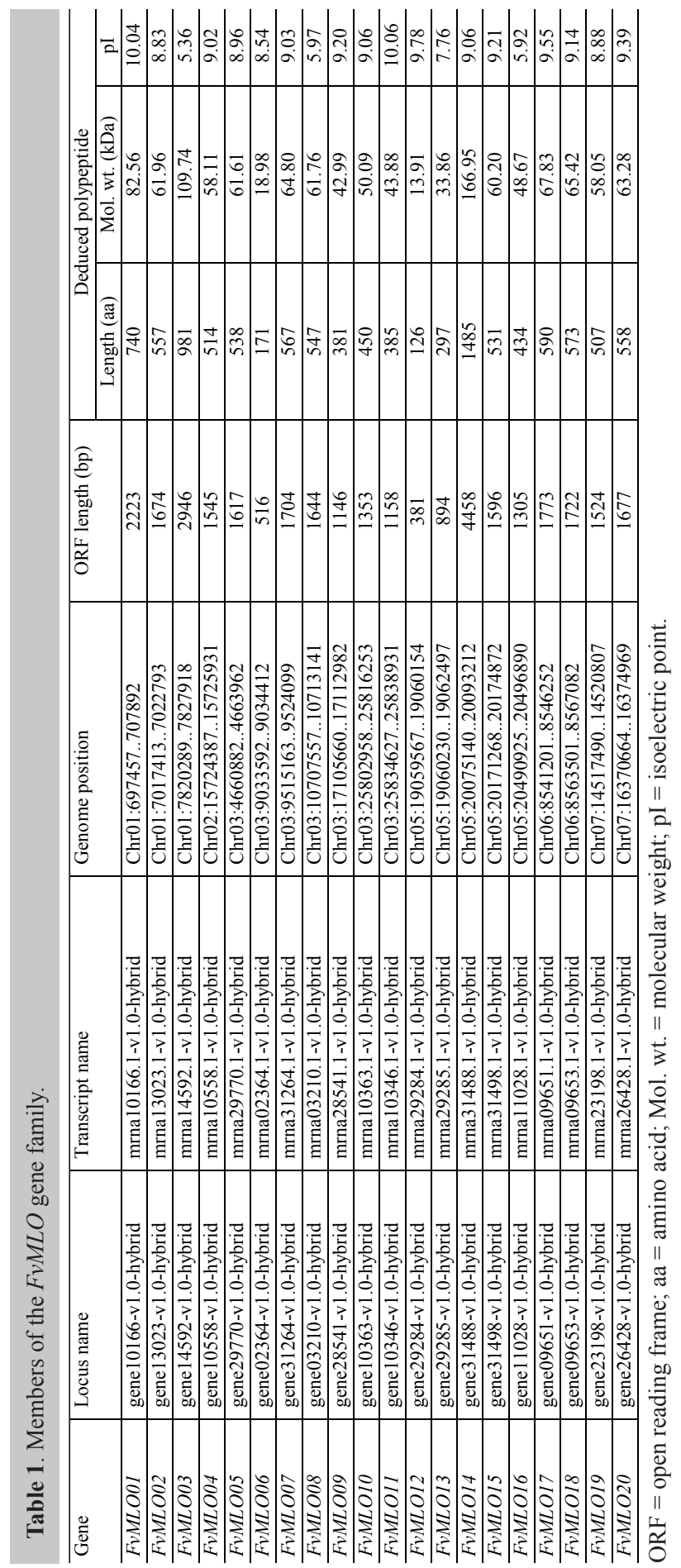

Genetics and Molecular Research 15 (3): gmr.15038400 


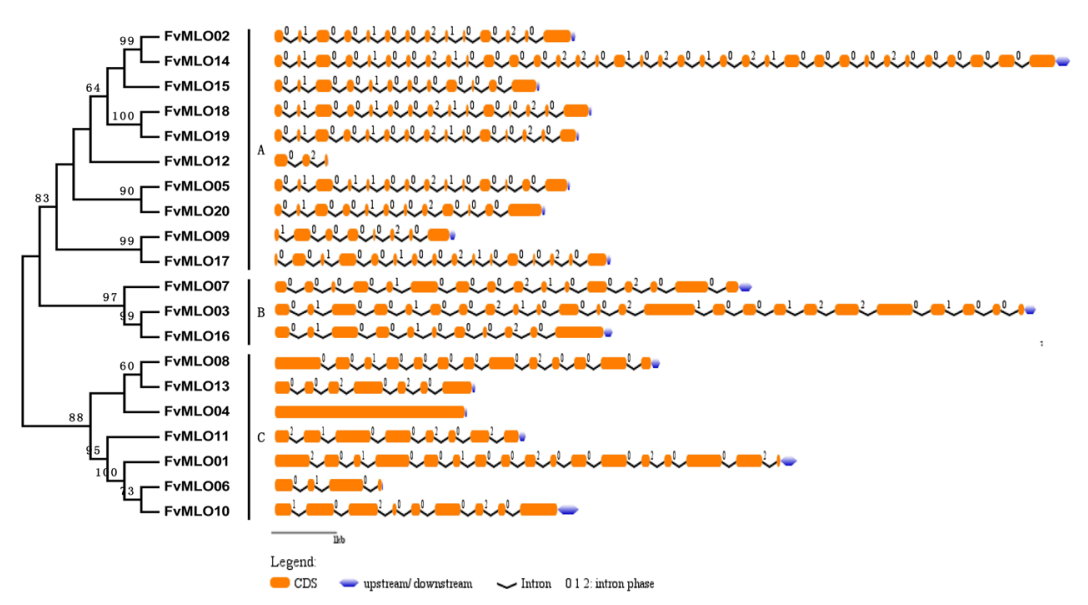

Figure 1. Phylogenetic analysis and intron/exon configurations of $F v M L O$ genes. Introns and exons are drawn to scale, with the full transcript regions of their respective genes. Boxes and lines indicate exons and introns, respectively. 0 , intron phrase $0 ; 1$, intron phrase $1 ; 2$, intron phrase 2 .

\section{Evolutionary relationships between $M L O$ s in different plant species}

The phylogenetic tree showed that $M L O$ s could be divided into seven groups (I-VII), with each group containing a different number of $M L O$ s (Figure 2). Group V contained the Arabidopsis AtMLO02, AtMLO06, and AtMLO12 genes, which are a specific group of PM resistance functions, as well as a tomato PM resistance gene (SIMLO) and four FvMLOs (FvMLO05, FvMLO18, FvMLO19, and FvMLO20), suggesting that these genes may be candidate genes for resistance to PM.

The phylogenetic tree was also used to identify homologous genes, and contained six pairs of orthologous genes and five pairs of paralogous genes. The former included one from wheat, one from strawberry, and four from $A$. thaliana. The latter included two from $A$. thaliana and strawberry, one from barley and rice, one from strawberry and grapevine, and one each from rice and maize. The woody grapevine $M L O$ s shared a common ancestry with the monocot maize and rice $M L O$ s. Three plant taxa (strawberry, grapevine, and poplar) had orthologous genes, indicating a common ancestry. In addition, three groups (I, II, and III) contained $M L O$ s from both monocots and dicots, suggesting that $M L O$ s were present before the divergence of monocots and dicots.

\section{Multiple sequence alignment}

In order to analyze the sequence characteristics of MLO proteins that are related to PM susceptibility, a multiple sequence alignment of MLO proteins from strawberry, Arabidopsis, tomato, and pea was conducted (Figure 3) (Consonni et al., 2006; Bai et al., 2008; Pavan et al., 2011). All of the FvMLO proteins had seven highly conserved transmembrane domains (TM17), which is a significant feature of the $M L O$ gene family (Devoto et al., 2003). A calmodulinbinding domain (CaMBD) that consists of an $\alpha$-helix with 10-15 extended amino acids (Kim et al., 2002a,b) in the C-terminus is highly conserved in FvMLOs. Panstruga (2005) identified two other conserved regions in the C-terminus of MLO proteins (I and II), which 
play important roles in modulating PM infection. These two peptide domains were located at the end of the C-terminus. Peptide domain I is characterized by conserved serine and threonine residues, while peptide domain II contains the consensus sequence D/E-F-S/T-F. In this study, we found that the peptide domains I and II were poorly conserved in the strawberry.

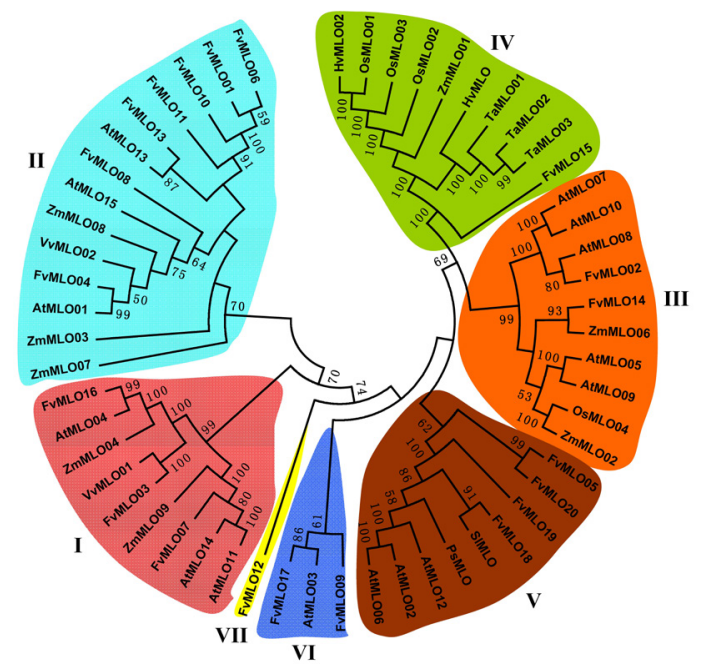

Figure 2. Phylogenetic comparison of $M L O$ genes from Arabidopsis, rice, grapevine, and strawberry. Numbers on the branches indicate the percentage of 1000 bootstrap replications that support the node (only values greater than $50 \%$ are presented).

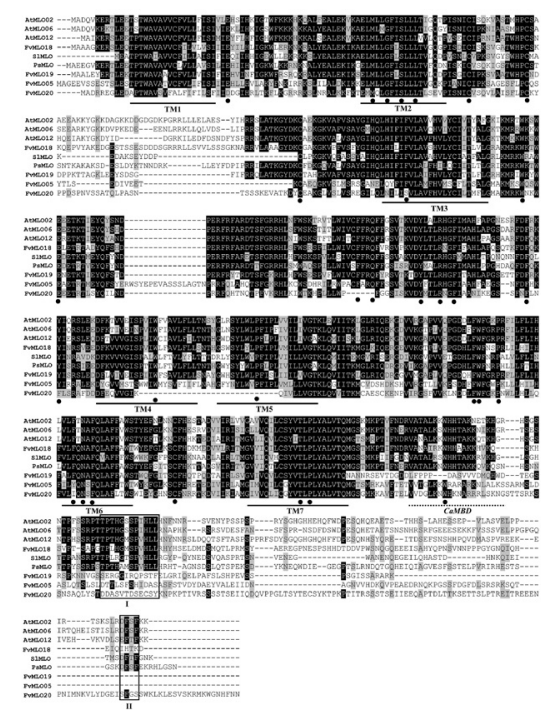

Figure 3. Multiple sequence alignment of MLO proteins from the $M L O$ genes in Group V (Figure 1) in the strawberry, with selected MLO proteins involved in PM susceptibility in pea (PsMLO), tomato (SIMLO), and Arabidopsis (AtMLO02, AtMLO06, and AtMLO12). Positions of the seven transmembrane domains (TM1-TM7) inferred from the experimentally determined topology of HvMLO and the approximate position of CaMBD are indicated by lines under the sequences. Two conserved domains (I and II) within the highly polymorphic C-termini are highlighted. 


\section{Chromosomal localization}

In order to elucidate the chromosomal distribution of $F v M L O$ s, we conducted in silico mapping. The $F v M L O$ s were on six of seven chromosomes (Figure 4). There were no $F v M L O$ s on chromosome 4, and only one (FvMLO04) on chromosome 2. Three and five FvMLOs were on chromosomes 1 and 5, respectively, and two were on each of chromosomes 6 and 7 . The remainder was on chromosome 3.

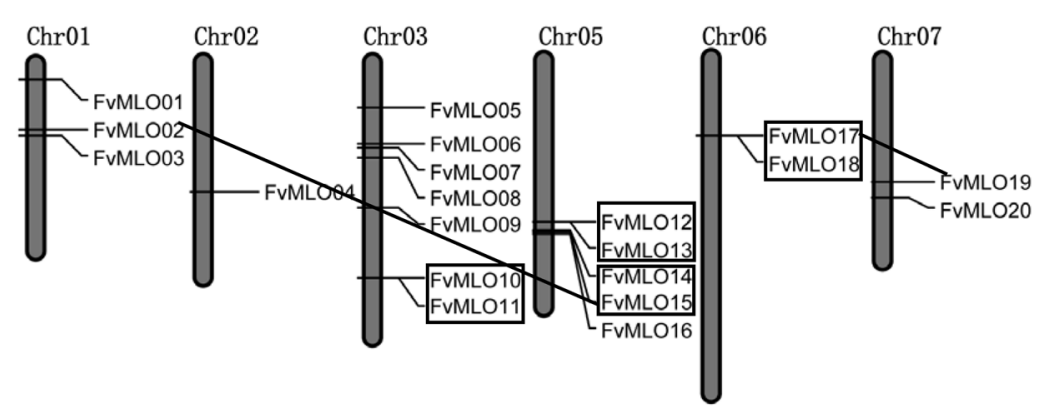

Figure 4. Mapping of $M L O$ genes on strawberry chromosomes. Chromosome numbers are indicated at the top of the chromosomes; those located on sequence scaffolds are not shown. Straight lines connecting the $M L O$ genes indicate duplicated chromosomal segments; tandem duplicated gene clusters are indicated by boxes.

Segmental and tandem duplication played important roles in $M L O$ family expansion during evolution (Cannon et al., 2004). In the present study, four pairs of genes (FvMLO10 and FvMLO11, FvMLO12 and FvMLO13, FvMLO14 and FvMLO15, and FvMLO17 and FvMLO18) exhibited tandem duplication (Figure 4). In addition, evidence of segmental genome duplication was found in the $F v M L O 02$ and $F v M L O 17$ chromosomal regions (Figure 4), which exhibited synteny with the surrounding genomic regions that contained $F v M L O 15$ and $F v M L O 19$, respectively.

\section{Conserved motifs of FvMLO proteins}

The FvMLO proteins had 10 types of conserved motifs; four motifs contained over 40 amino acids (Motif 01, Motif 03, Motif 04, and Motif 06), and the remainder contained between 21 and 30 amino acids (Table 2). We analyzed the distributions of these conserved motifs (Figure 5), and found that most of the FvMLO proteins contained all motif types, but not three of them (FvMLO06, FvMLO11, and FvMLO12). The distributions of the conserved motifs were consistent with the phylogenic relationships between the FvMLO proteins.

\section{In silico analysis of $F v M L O$ expression using EST libraries}

To evaluate the expression profiles of $F v M L O$ s under different stressors, a BLAST search was performed using the $F v M L O$ coding sequences in the Genome Database for Rosaceae. Only 11 predicted genes had corresponding ESTs in the database (Table 3). Of these, three (FvMLO01, $F v M L O 10$, and $F v M L O 11)$ were induced by high salinity, four ( $F v M L O 03, F v M L O 07$, $F v M L O 09$, and $F v M L O 19$ ) by low temperature, four (FvMLO04, FvMLO12, FvMLO13, and $F v M L O 18$ ) by high temperature, and $F v M L O 04$ by high temperature and drought. 
Table 2. Motif compositions of FvMLO proteins.

\begin{tabular}{l|c|l}
\hline Motif & Width & Best possible match \\
\hline Motif 01 & 44 & QYGFDSCFMENIEYIIPRLVMGVFVQFLCSYSTLPLYAIVTQMG \\
\hline Motif 02 & 41 & DPVVQPSDDHFWFNRPRWVLHLIHFILFQNAFEMAFFFWIW \\
\hline Motif 03 & 30 & LEKIKEELMLLGFISLLLTVFQDPIAKICI \\
\hline Motif 04 & 43 & CKKGKVPFVSYNGLHQLHIFIFVLAIFHVVYCCLTMALGMAKM \\
\hline Motif 05 & 29 & CFFRQFYGSVTKVDYMTMRHGFINAHCA \\
\hline Motif 06 & 41 & LEYTPTWAVATVCFVIVFISIIIEHIHCLGKWLKRRRKKA \\
\hline Motif 07 & 27 & NFDFHKYMKRSLEDDFKVVVGISPIMW \\
\hline Motif 08 & 21 & GTKLQHIITQMAHEIAEKHNV \\
\hline Motif 09 & 28 & SNMKKAIFDEHVQEGLKGWHKDAKKHQA \\
\hline Motif 10 & 28 & EYQFSNDPNRFRYTHQTSFGKRHLKFWT \\
\hline
\end{tabular}

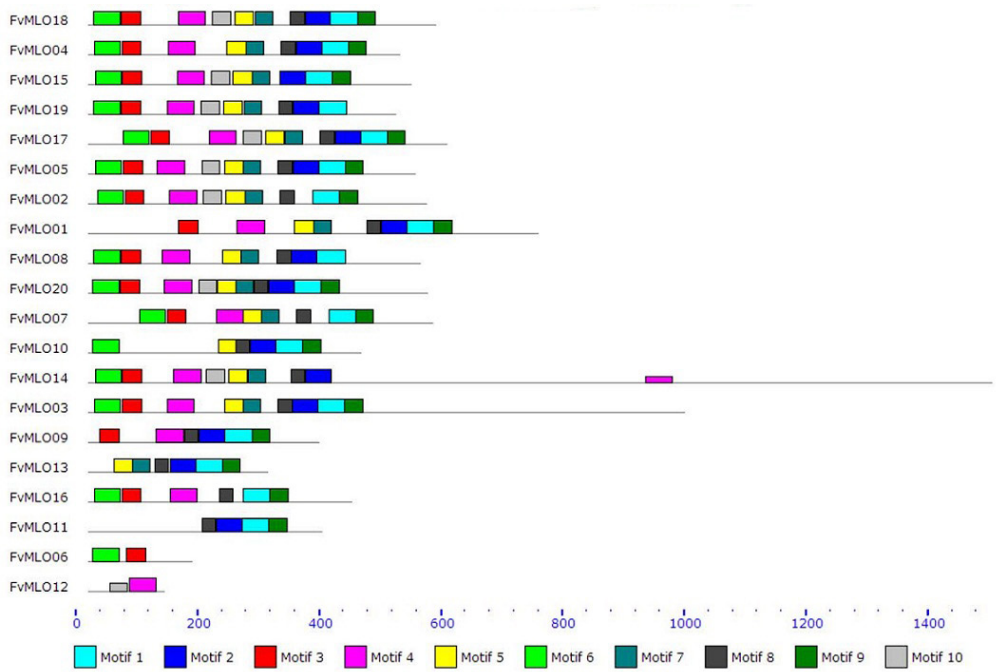

Figure 5. Motif structure of $M L O$ genes in the strawberry.

Table 3. Expressed sequence tag (EST)-derived expression profiles of $F v M L O$ genes in stressed seedlings.

\begin{tabular}{l|c|c|c|c}
\hline Name & High salinity & Low temperature & High temperature & Drought \\
\hline FvMLO01 & + & & & \\
\hline FvMLO02 & & & & \\
\hline FvMLO03 & & & & \\
\hline FvMLO04 & & & & \\
\hline FvMLO05 & & & & \\
\hline FvMLO06 & & & & \\
\hline FvMLO07 & & & & \\
\hline FvMLO08 & + & & & \\
\hline FvMLO09 & & & & \\
\hline FvMLO10 & & & & \\
\hline FvMLO11 & & & & \\
\hline FvMLO12 & & & & \\
\hline FvMLO13 & & & & \\
\hline FvMLO14 & & & & \\
\hline FvMLO15 & & & & \\
\hline FvMLO16 & & & & \\
\hline FvMLO17 & & & & \\
\hline FvMLO18 & & & & \\
\hline FvMLO19 & & & & \\
\hline FvMLO20 & & & & \\
\hline
\end{tabular}

Genetics and Molecular Research 15 (3): gmr.15038400 


\section{DISCUSSION}

In order to analyze the phylogenic relationships between $M L O$ s, dicots, monocots, and woody plant $M L O$ s were investigated in this study. According to a previous classification of Arabidopsis $M L O$ s, $F v M L O$ s could be divided into seven groups (I-VII). Only three groups (I, II, and III) contained $M L O$ s from all of the species tested, indicating that the members of these three groups were more conserved than those in the remaining four groups. In addition, six pairs of orthologous genes and five pairs of paralogs were identified in the phylogenetic tree, suggesting a common ancestry of $M L O \mathrm{~s}$ in these plant species. Six pairs of orthologous genes were in Arabidopsis with four pairs, as well as in wheat with one pair and strawberry with one pair; therefore, wheat, strawberry, and Arabidopsis have orthologous genes, indicating that $M L O$ s underwent gene duplication after the divergence of the monocots and dicotsl.

Given that Group V, which included Arabidopsis AtMLO02, AtMLO06, AtMLO12, pea $P S M L O$, and tomato $S I M L O$, indicates the putative functions of $M L O \mathrm{~s}$ in many plant species, we inferred that this group is significant for strawberry, as these $M L O$ s are required for PM susceptibility (Consonni et al., 2006; Bai et al., 2008; Pavan et al., 2011). Therefore, this group may be dicot-specific. Four MLOs ( FvMLO05, FvMLO18, FvMLO19, and FvMLO20) were in Group V, suggesting that they may be candidate PM resistance genes. In addition, in the multiple sequence alignment, these genes not only contained seven highly conserved transmembrane domains and the CaMBD domain of the $M L O$ gene family, but also two conserved peptide regions (I and II) in the C-terminal.

At present, two types of gene duplication events have been identified during the evolution of gene families: tandem and segmental duplication. The former may result in a clustered occurrence of family members, whereas the latter may result in a scattered occurrence of family members (Schauser et al., 2005). Both types of duplication event were observed in this study, indicating that the expansion of the $F v M L O$ family mainly resulted from segmental and tandem duplication.

Many sequences that are available from EST libraries (e.g., http://www.rosaceae.org/) can provide useful information regarding gene expression analysis. In this study, 12 ESTs were identified for $11 F v M L O$ s, and most of them were expressed under different stressors (Table 3), indicating that $F v M L O$ s may be involved in plant growth and development. The large number of $F v M L O$ s found in this study will provide useful information for further experimental verification.

In conclusion, we conducted a genome-wide identification and analysis of $F v M L O \mathrm{~s}$ using bioinformatics. At least $20 \mathrm{FvMLOs}$ were identified, and their structures, phylogenies, and sequence characteristics were analyzed. These results will provide a foundation for the breeding of strawberries that are resistant to PM.

\section{Conflicts of interest}

The authors declare no conflicts of interest.

\section{ACKNOWLEDGMENTS}

Research supported by the National Natural Science Foundation of China (Grant \#31201613), the Young Talent Training Program of Zhejiang Academy of Agricultural Sciences (Grant \#2015R05R08E01), and the New Cultivar Breeding Program of Zhejiang Province (Grant \#2012C12904).

Genetics and Molecular Research 15 (3): gmr.15038400 


\section{REFERENCES}

Alam MA, Hongpo W, Hong Z and Ji WQ (2014). Differential expression of resistance to powdery mildew at the early stage of development in wheat line N0308. Genet. Mol. Res. 13: 4289-4301.http://dx.doi.org/10.4238/2014.June.9.15

Amsalem L, Freeman S, Rav-David D, Nitzani Y, et al. (2006). Effect of climatic factors on powdery mildew caused by Sphaerotheca macularis f. sp. fragariae on strawberry. Eur. J. Plant Pathol. 114: 283-292. http://dx.doi.org/10.1007/ $\underline{\mathrm{s} 10658-005-5804-6}$

Bai Y, Pavan S, Zheng Z, Zappel NF, et al. (2008). Naturally occurring broad-spectrum powdery mildew resistance in a Central American tomato accession is caused by loss of mlo function. Mol. Plant Microbe Interact. 21: 30-39. http:// dx.doi.org/10.1094/MPMI-21-1-0030

Boesewinkel HJ (1979). Differences between the conidial states of Podosphaera tridactyla and Sphaerotheca pannosa. Ann. Phytopathol. 11: 525-527.

Büschges R, Hollricher K, Panstruga R, Simons G, et al. (1997). The barley Mlo gene: a novel control element of plant pathogen resistance. Cell 88: 695-705. http://dx.doi.org/10.1016/S0092-8674(00)81912-1

Cannon SB, Mitra A, Baumgarten A, Young ND, et al. (2004). The roles of segmental and tandem gene duplication in the evolution of large gene families in Arabidopsis thaliana. BMC Plant Biol. 4: 10.http://dx.doi.org/10.1186/1471$\underline{2229-4-10}$

Consonni C, Humphry ME, Hartmann HA, Livaja M, et al. (2006). Conserved requirement for a plant host cell protein in powdery mildew pathogenesis. Nat. Genet. 38: 716-720. http://dx.doi.org/10.1038/ng1806

Devoto A, Piffanelli P, Nilsson I, Wallin E, et al. (1999). Topology, subcellular localization, and sequence diversity of the Mlo family in plants. J. Biol. Chem. 274: 34993-35004. http://dx.doi.org/10.1074/jbc.274.49.34993

Devoto A, Hartmann HA, Piffanelli P, Elliott C, et al. (2003). Molecular phylogeny and evolution of the plant-specific seven-transmembrane MLO family. J. Mol. Evol. 56: 77-88. http://dx.doi.org/10.1007/s00239-002-2382-5

Feechan A, Jermakow AM, Torregrosa L, Panstruga R, et al. (2009). Identification of grapevine $M L O$ gene candidates involved in susceptibility to powdery mildew. Funct. Plant Biol. 35: 1255-1266. http://dx.doi.org/10.1071/FP08173

Foulongne M, Pascal T, Pfeiffer F and Kervella J (2003). QTLs for powdery mildew resistance in peach $\times$ Prunus davidiana crosses: consistency across generations and environments. Mol. Breed. 12: 33-50. http://dx.doi. org/10.1023/A:1025417507358

Guo AY, Zhu QH, Chen XL and Jing C (2007). GSDS: Gene structure display system. Heredity 29: 1023-1026.

Heejeong J, Jaewook A, Haesuk Y, Minkeun K, et al. (2015). Development of cleaved amplified polymorphic sequence (caps) marker for selecting powdery mildew-resistance line in strawberry. Korean J. Hort. Sci. Technol 33: 722-729. http://dx.doi.org/10.7235/hort.2015.14133

Jiwan D, Roalson EH, Main D and Dhingra A (2013). Antisense expression of peach mildew resistance locus O (PpMlo1) gene confers cross-species resistance to powdery mildew in Fragaria x ananassa. Transgenic Res. 22: 1119-1131. http://dx.doi.org/10.1007/s11248-013-9715-6

Kim MC, Panstruga R, Elliott C, Müller J, et al. (2002a). Calmodulin interacts with MLO protein to regulate defence against mildew in barley. Nature 416: 447-451.http://dx.doi.org/10.1038/416447a

Kim MC, Lee SH, Kim JK, Chun HJ, et al. (2002b). Mlo, a modulator of plant defense and cell death, is a novel calmodulinbinding protein. Isolation and characterization of a rice Mlo homologue. J. Biol. Chem. 277: 19304-19314. http:// dx.doi.org/10.1074/jbc.M108478200

Liu Q and Zhu H (2008). Molecular evolution of the MLO gene family in Oryza sativa and their functional divergence. Gene 409: 1-10. http://dx.doi.org/10.1016/j.gene.2007.10.031

Liu RH and Meng JL (2003). [MapDraw: a microsoft excel macro for drawing genetic linkage maps based on given genetic linkage data]. Yi Chuan 25: 317-321.

Lu M, Wang L, Zhang J, Sun S, et al. (2014). Molecular cytogenetic identification of a novel 1AL.1RS translocation line with powdery mildew resistance. Genet. Mol. Res. 13: 10678-10689. http://dx.doi.org/10.4238/2014.December.18.10

Panstruga R (2005). Discovery of novel conserved peptide domains by ortholog comparison within plant multi-protein families. Plant Mol. Biol. 59: 485-500. http://dx.doi.org/10.1007/s11103-005-0353-0

Pavan S, Schiavulli A, Appiano M, Marcotrigiano AR, et al. (2011). Pea powdery mildew er1 resistance is associated to loss-of-function mutations at a MLO homologous locus. Theor. Appl. Genet. 123: 1425-1431. http://dx.doi. org $/ 10.1007 / \mathrm{s} 00122-011-1677-6$

Pessina S, Pavan S, Catalano D, Gallotta A, et al. (2014). Characterization of the $M L O$ gene family in Rosaceae and gene expression analysis in Malus domestica. BMC Genomics 15: 618. http://dx.doi.org/10.1186/1471-2164-15-618

Piffanelli P, Ramsay L, Waugh R, Benabdelmouna A, et al. (2004). A barley cultivation-associated polymorphism conveys resistance to powdery mildew. Nature $430: 887-891$.http://dx.doi.org/10.1038/nature02781

Genetics and Molecular Research 15 (3): gmr.15038400 
Schauser L, Wieloch W and Stougaard J (2005). Evolution of NIN-like proteins in Arabidopsis, rice, and Lotus japonicus. J. Mol. Evol. 60: 229-237. http://dx.doi.org/10.1007/s00239-004-0144-2

Sun JJ, Wang ZY, Shen JY, Shen YZ, et al. (2015). Global transcriptome analysis and identification of differentially expressed genes after infection of Fragaria vesca with powdery mildew (Podosphaera aphanis). Transcriptomics 2: 106.

Tamura K, Peterson D, Peterson N, Stecher G, et al. (2011). MEGA5: molecular evolutionary genetics analysis using maximum likelihood, evolutionary distance, and maximum parsimony methods. Mol. Biol. Evol. 28: 2731-2739. http://dx.doi.org/10.1093/molbev/msr121

Turechek WW, Carroll JE and Rosenberger DA (2004). Powdery mildew of apple. New York State Integrated Pest Management Program, Cornell University. http://www.nysipm.cornell.edu/factsheets/treefruit/diseases/pm/apple pm.pdf.

Xiao CL, Chandler CK, Price JF, Duval JR, et al. (2001). Comparison of epidemics of botrytis fruit rot and powdery mildew of strawberry in large plastic tunnel and field production systems. Plant Dis. 85: 901-909. http://dx.doi. org/10.1094/PDIS.2001.85.8.901

Zhang J, Zhang Y, Yu H and Wang Y (2014). Evaluation of powdery mildew-resistance of grape germplasm and rapid amplified polymorphic DNA markers associated with the resistant trait in Chinese wild Vitis. Genet. Mol. Res. 13: 3599-3614. http://dx.doi.org/10.4238/2014.May.9.3

Zhou SJ, Jing Z and Shi JL (2013). Genome-wide identification, characterization, and expression analysis of the $M L O$ gene family in Cucumis sativus. Genet. Mol. Res. 12: 6565-6578. http://dx.doi.org/10.4238/2013.December.11.8

Genetics and Molecular Research 15 (3): gmr.15038400 